\title{
Correlation between vascular endothelial growth factor and nonperfused areas in macular edema secondary to branch retinal vein occlusion
}

This article was published in the following Dove Press journal:

Clinical Ophthalmology

18 July 2013

Number of times this article has been viewed

\section{Masato Fujikawa \\ Osamu Sawada \\ Taichiro Miyake \\ Masashi Kakinoki \\ Tomoko Sawada \\ Hajime Kawamura \\ Masahito Ohji}

Department of Ophthalmology, Shiga University of Medical Science, Otsu, Japan
Correspondence: Masato Fujikawa Department of Ophthalmology, Shiga University of Medical Science, Seta Tsukinowa-cho, Otsu,

Shiga 520-2192, Japan

Tel +8I 775482276

Fax +8I 775482279

Email fujikawa@belle.shiga-med.ac.jp
Purpose: To determine the role of vascular endothelial growth factor (VEGF) in macular edema secondary to branch retinal vein occlusion (BRVO).

Patients and methods: Aqueous humor samples were collected from 52 eyes with macular edema secondary to BRVO before intravitreal drug injections and from 62 control eyes with cataract. VEGF was measured using an enzyme-linked immunosorbent assay. Fluorescein angiography showed capillary nonperfused areas (NPAs). Macular edema was evaluated by optical coherence tomography as the central retinal thickness.

Results: The mean aqueous VEGF levels in eyes with BRVO and control eyes with cataract were, respectively, $290.5 \mathrm{pg} / \mathrm{mL} \pm 294.9 \mathrm{pg} / \mathrm{mL}$ (range $81.9 \mathrm{pg} / \mathrm{mL}-1567.3 \mathrm{pg} / \mathrm{mL}$ ) and $118.0 \mathrm{pg} / \mathrm{mL} \pm 50.1 \mathrm{pg} / \mathrm{mL}$ (range $24.6 \mathrm{pg} / \mathrm{mL}-241.1 \mathrm{pg} / \mathrm{mL}$ ), which differed significantly $(P<0.0001)$. The mean VEGF level in eyes with BRVO without apparent NPA was $171.4 \mathrm{pg} / \mathrm{mL} \pm 52.5 \mathrm{pg} / \mathrm{mL}$ (range $90.9 \mathrm{pg} / \mathrm{mL}-299.9 \mathrm{pg} / \mathrm{mL}$ ), which was significantly higher than controls $(P=0.001)$. VEGF levels were correlated positively with the size of NPA $(P=0.0002)$ but not with the central retinal thickness.

Conclusion: The aqueous VEGF concentration in patients with macular edema secondary to BRVO increased significantly and was correlated significantly with the size of NPA. Aqueous VEGF increased even in eyes without apparent NPA.

Keywords: aqueous humor, branch retinal vein occlusion, macular edema

\section{Introduction}

Branch retinal vein occlusion (BRVO), a common retinal vascular disease, is often associated with macular edema, which is the most frequent cause of visual impairment in these patients. ${ }^{1,2}$ Thus, it is critical to determine the cellular and molecular factors that underlie the pathogenesis of macular edema secondary to BRVO. Intraocular levels of cytokines, such as vascular endothelial growth factor (VEGF) and interleukin (IL)-6, have been reported to increase in retinal vein occlusion. ${ }^{3-5}$

VEGF produced in the retina may play a key role in the pathogenesis of macular edema secondary to BRVO, similar to other retinal vascular diseases, such as proliferative diabetic retinopathy and retinopathy of prematurity. ${ }^{3}$ VEGF causes a marked increase in vascular permeability by provoking conformational changes in the tight junctions of the retinal vascular endothelial cell. ${ }^{6-8}$ Intravitreal injection of bevacizumab (Avastin; Genentech, San Francisco, CA, USA), a full-length humanized monoclonal antibody that binds and inhibits all biologically active forms of $\mathrm{VEGF},{ }^{9}$ is effective for treating macular edema secondary to retinal vein occlusion. ${ }^{10,11}$ These findings suggest that VEGF may contribute to the development of macular edema secondary to BRVO. 
Noma et al reported that VEGF levels increased in the vitreous fluid with macular edema associated with BRVO and were correlated positively with both the size of the nonperfused area (NPA) and the retinal thickness resulting from macular edema. ${ }^{12-14}$ However, these reports included eyes that had been treated previously with photocoagulation therapy, which may have affected the VEGF concentration, making an understanding of the pathogenesis difficult. Furthermore, the VEGF levels in eyes with BRVO without an NPA are poorly understood. Therefore, we measured the VEGF concentrations in the aqueous humor in a large number of treatment-naive patients with macular edema secondary to BRVO with or without NPA and investigated the relation between aqueous VEGF levels and the clinical conditions of BRVO.

\section{Materials and methods}

We prospectively measured the VEGF concentrations in the aqueous humor of 52 eyes of 52 patients ( 29 women, 23 men) with macular edema secondary to BRVO. The mean patient age was 68.0 years \pm 10.0 years (range 39 years -90 years).

The inclusion criteria were treatment-naive BRVO in eyes that had not undergone any previous treatments, including photocoagulation therapy, sub-Tenon's injection of triamcinolone acetonide or intravitreal injection of steroids, tissue plasminogen activator, or anti-VEGF drugs; central retinal thickness (CRT) exceeding $300 \mu \mathrm{m}$; bestcorrected visual acuity (BCVA) of 0.5 or worse measured with the Landolt $\mathrm{C}$ chart; no diabetes mellitus; and no thick hemorrhages that obscured fundus visualization. For statistical analysis, the BCVA values were converted to the logarithm of the minimum angle of resolution ( $\log$ MAR).

We also obtained aqueous humor from 62 eyes of 62 ageadjusted control patients (39 women, 23 men; mean age 70.9 years \pm 9.3 years; range 44 years -82 years) with cataract alone. None of the 62 patients had diabetes mellitus.

Aqueous humor samples were collected from the BRVO group immediately before intravitreal injection of either triamcinolone acetonide or bevacizumab and from the control group just before cataract surgery.

All intravitreal injections were administered, and samples were collected using a standard sterilization procedure that included instillation of topical povidone-iodine and antibiotic drops. All samples were stored in a deep freezer at $-80^{\circ} \mathrm{C}$ until analysis. The VEGF concentrations were measured using an enzyme-linked immunosorbent assay (ELISA) for human VEGF (Human VEGF Quantikine ELISA Kit; R\&D
Systems, Minneapolis, MN, USA); the primary antibody targeted two VEGF isoforms: $\mathrm{VEGF}_{121}$ and $\mathrm{VEGF}_{165^{\circ}}$. The lowest detectable limit of VEGF concentration was $9 \mathrm{pg} / \mathrm{mL}$, according to the manufacturer's instructions.

Fluorescein angiography (FA) was performed to detect the NPAs before treatment. The sizes of the NPAs were analyzed with Scion Image software (Scion, Frederick, MD, USA) and expressed in disc areas (DAs). We divided the BRVO group into two subgroups for further analysis based on the presence (+) or absence (-) of a NPA. The NPA ${ }^{+}$group included eyes with an NPA observed on FA, and the NPA ${ }^{-}$ group included eyes without apparent NPA on FA. Optical coherence tomography (OCT) was performed using Stratus OCT (Carl Zeiss Meditec, Dublin, CA, USA), and the CRT was analyzed using the fast macular thickness-scan pattern protocol that averages the retinal thickness within $1 \mathrm{~mm}$ in diameter over the central fovea. Existence of subretinal fluid (SRF) was also analyzed by OCT. Sample data were analyzed using GraphPad Prism 6 software (GraphPad Software, La Jolla, CA, USA).

Unpaired $t$-test was used to compare the two independent groups with normal distribution. The Mann-Whitney test was used to compare the two independent groups without normal distribution. Spearman's $r$ correlation test was used to analyze the correlation between the VEGF concentrations and the CRT and the size of the NPA in eyes with BRVO. $P<0.05$ was considered significant.

The institutional review board of Shiga University of Medical Science Hospital approved this study, which followed the principles of the Declaration of Helsinki. All participants provided written informed consent before the start of the study.

\section{Results}

Based on the presence of an NPA on FA, 52 eyes with BRVO were divided into two subgroups: $\mathrm{NPA}^{+}(39$ eyes, $75.0 \%)$ and $\mathrm{NPA}^{-}$(13 eyes, $\left.25.0 \%\right)$.

In the 52 eyes with BRVO, the mean $\log$ MAR BCVA was $0.610 \pm 0.262$ (range 0.301-1.398). The mean CRT was $557.3 \mu \mathrm{m} \pm 175.5 \mu \mathrm{m}$ (range $205 \mu \mathrm{m}-109 \mu \mathrm{m}$ ). SRF was detected in $22(42.3 \%)$ of 52 eyes with BRVO. The mean period between the onset of BRVO and sample collection was 5.0 months \pm 4.6 months (range 0 DAs -171.3 DAs). The mean size of NPA was 32.2 DAs \pm 38.2 DAs (range 0 DAs-171.3 DAs).

The mean aqueous VEGF concentrations in the eyes with BRVO were $290.5 \mathrm{pg} / \mathrm{mL} \pm 294.9 \mathrm{pg} / \mathrm{mL}$ (range $81.9 \mathrm{pg} / \mathrm{mL}-1567.3 \mathrm{pg} / \mathrm{mL}$ ) and $118.0 \mathrm{pg} / \mathrm{mL} \pm 50.1 \mathrm{pg} / \mathrm{mL}$ 


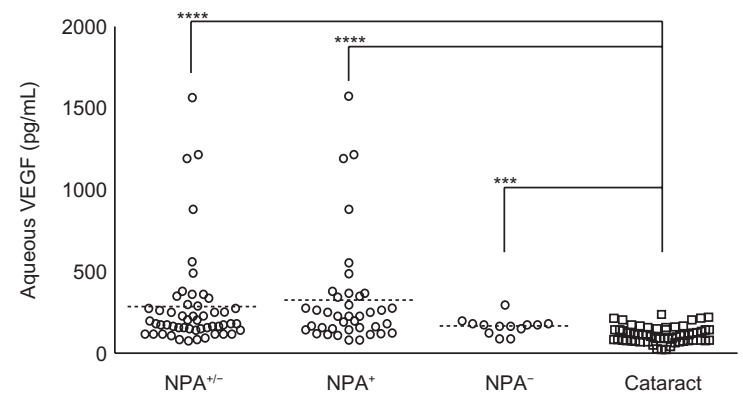

Figure I Aqueous VEGF levels of all BRVO eyes $\left(\mathrm{NPA}^{+--}\right)$, NPA ${ }^{+}$group, and NPA group were significantly higher than the control cataract group.

Note: $* * * * P<0.0001$; *** $P=0.0009$; dashed lines stand for mean.

Abbreviations: BRVO, branch retinal vein occlusion; NPA, nonperfused area; VEGF, vascular endothelial growth factor.

(24.6 pg/mL-241.1 pg/mL) in the control group. The mean VEGF concentration was significantly higher in eyes with BRVO than in the control cataract eyes $(P<0.0001$ by Mann-Whitney test). The mean aqueous VEGF concentration in the $\mathrm{NPA}^{-}$group was $171.4 \mathrm{pg} / \mathrm{mL} \pm 52.5 \mathrm{pg} / \mathrm{mL}$ $(90.9 \mathrm{pg} / \mathrm{mL}-299.9 \mathrm{pg} / \mathrm{mL})$, which was significantly higher than in the control cataract eyes $(P=0.0009$ by unpaired $t$-test). The aqueous VEGF concentration was $330.2 \mathrm{pg} / \mathrm{mL} \pm 330.7 \mathrm{pg} / \mathrm{mL}(81.9 \mathrm{pg} / \mathrm{mL}-1567.3 \mathrm{pg} / \mathrm{mL})$ in the $\mathrm{NPA}^{+}$group, which was also significantly higher than in the control cataract eyes $(P<0.0001$ by Mann-Whitney test) (Figure 1). The mean aqueous VEGF concentration in the $\mathrm{NPA}^{+}$group was higher than in the $\mathrm{NPA}^{-}$group; however, the difference did not reach significance ( $P=0.0852$ by Mann-Whitney test) (Table 1).

In BRVO eyes with SRF $(n=22)$, the mean aqueous VEGF concentration, the size of NPA, and the CRT were $220.5 \mathrm{pg} / \mathrm{mL} \pm 90.3 \mathrm{pg} / \mathrm{mL}, 36.9 \mathrm{DAs} \pm 39.5 \mathrm{DAs}$, and $631.5 \mu \mathrm{m} \pm 199.9 \mu \mathrm{m}$, respectively. In BRVO eyes without SRF $(\mathrm{n}=30)$, they were $341.8 \mathrm{pg} / \mathrm{mL} \pm 374.9 \mathrm{pg} / \mathrm{mL}, 28.7$ DAs \pm 37.5 DAs, and $502.9 \mu \mathrm{m} \pm 134.2 \mu \mathrm{m}$, respectively. Statistical significance was found in CRT ( $P=0.0077$ by unpaired $t$-test), but not in the aqueous VEGF concentration
( $P=0.9483$ by Mann-Whitney test $)$ and the NPA $(P=0.201$ by Mann-Whitney test).

In all 52 eyes with BRVO, the size of the NPA was positively significantly correlated with the aqueous VEGF concentration (Spearman's $r=0.488, P=0.0002$ ) (Figure 2). However, no correlation was found between the aqueous VEGF concentration and the CRT (Spearman's $r=0.186$, $P=0.187$ ) (Figure 3).

\section{Discussion}

Macular edema secondary to BRVO is a frequent cause of visual impairment. However, no effective treatment has been established, although various treatments have been attempted. ${ }^{11,15-18}$ To determine an effective treatment, the pathogenesis of the macular edema secondary to BRVO must be determined. VEGF is a primary cytokine that contributes to the development of macular edema. VEGF expression is promoted by hypoxia, and causes changes in the conformational structure of the tight junctions of the retinal vascular endothelial cells and induces increased vascular permeability. ${ }^{6-8}$ The aqueous and vitreous VEGF levels increase in eyes with proliferative diabetic retinopathy, diabetic macular edema, central retinal vein occlusion, and BRVO. ${ }^{3,12-14}$

Noma et al reported that the aqueous VEGF level in 19 eyes with macular edema associated with BRVO was $351 \mathrm{pg} / \mathrm{mL} \pm 273 \mathrm{pg} / \mathrm{mL}$, which was significantly higher compared with the control group. They included nine patients who had undergone previous photocoagulation therapy before sample collection. ${ }^{12}$ The previous treatment might have affected the production of VEGF in BRVO eyes. ${ }^{3}$ Therefore, the current study included 52 treatment-naive eyes with BRVO with macular edema alone. The aqueous VEGF concentration in eyes with macular edema secondary to treatment-naive BRVO was $290.5 \mathrm{pg} / \mathrm{mL} \pm 294.9 \mathrm{pg} / \mathrm{mL}$, which was significantly higher than in the control eyes

Table I Demographic data in BRVO subgroup

\begin{tabular}{|c|c|c|c|c|c|}
\hline & \multicolumn{2}{|c|}{$\mathrm{NPA}^{+}(n=39)$} & \multicolumn{2}{|c|}{$\operatorname{NPA}^{-}(n=13)$} & \multirow[t]{2}{*}{$P$} \\
\hline & Mean \pm SD & Range & Mean \pm SD & Range & \\
\hline Age (years) & $67.3 \pm 10.5$ & $39-90$ & $70.3 \pm 8.3$ & $58-88$ & $0.3449^{a}$ \\
\hline Interval* (months) & $4.6 \pm 4.1$ & $0.7-18.0$ & $5.9 \pm 5.5$ & $0.8-17.3$ & $0.5762^{\mathrm{b}}$ \\
\hline LogMAR VA & $0.642 \pm 0.27 I$ & $0.301-1.398$ & $0.513 \pm 0.214$ & $0.30 I-1.000$ & $0.125^{\mathrm{a}}$ \\
\hline CRT $(\mu \mathrm{m})$ & $601.4 \pm 177.7$ & $205-1095$ & $424.9 \pm 75.2$ & $319-576$ & $0.00 \mathrm{II}^{\mathrm{a}}$ \\
\hline NPA (DA) & $42.9 \pm 38.5$ & $4.1-|7| .3$ & 0 & - & $<0.000 \mathrm{I}^{\mathrm{b}}$ \\
\hline VEGF (pg/mL) & $330.2 \pm 330.7$ & $81.9-1567.3$ & $171.4 \pm 52.5$ & 90.9-299.9 & $0.0852^{\mathrm{b}}$ \\
\hline
\end{tabular}

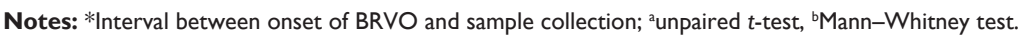

Abbreviations: BCVA, best-corrected visual acuity; BRVO, branch retinal vein occlusion; CRT, central retinal thickness; LogMAR VA, logarithm of minimum angle of resolution - visual acuity; NPA, nonperfused area; SD, standard deviation; VEGF, vascular endothelial growth factor. 


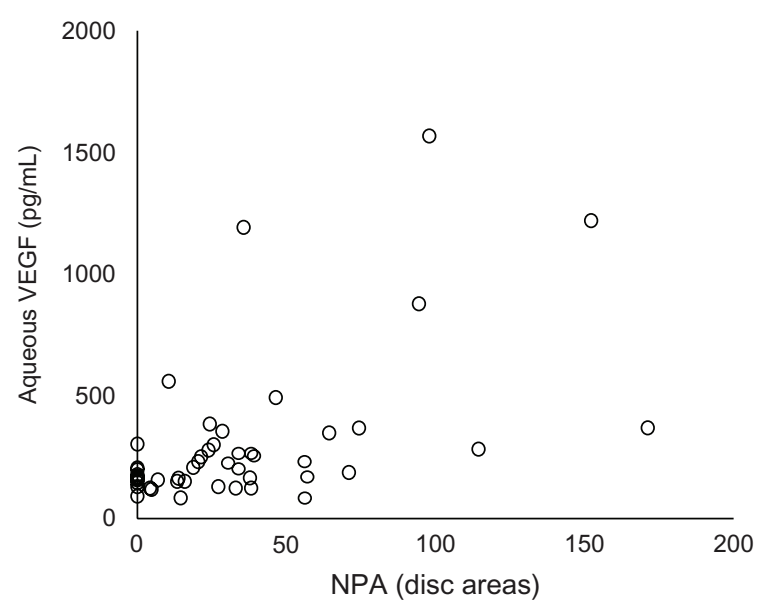

Figure 2 The size of the NPA was positively significantly correlated with the aqueous VEGF concentration (Spearman's $r=0.488, P=0.0002$ ) in BRVO. Abbreviations: BRVO, branch retinal vein occlusion; NPA, nonperfused area; VEGF, vascular endothelial growth factor.

with cataract. We confirmed that the VEGF concentration was elevated in treatment-naive eyes with macular edema secondary to BRVO, which was similar to the results reported by Noma et al, ${ }^{12}$ which included eyes with a history of photocoagulation therapy.

It has been reported that ischemic BRVO tends to occur in serous retinal detachment. ${ }^{19}$ Therefore, we selected 13 of 52 eyes with BRVO without apparent NPA seen on FA. Even in eyes without NPA, the aqueous VEGF concentration was $171.4 \mathrm{pg} /$ $\mathrm{mL} \pm 52.5 \mathrm{pg} / \mathrm{mL}$, which was significantly higher than the control group, suggesting that the presence of microischemic lesion undetectable by FA might be responsible for increased VEGF concentrations. The difference in the aqueous VEGF

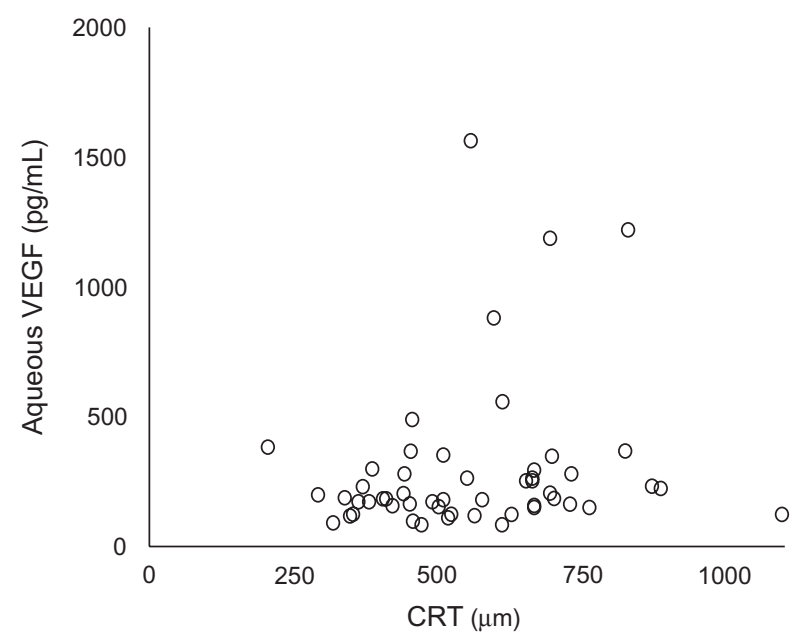

Figure 3 The CRT was not correlated with the aqueous VEGF concentration (Spearman's $r=0.186, P=0.187$ ) in BRVO.

Abbreviations: CRT, central retinal thickness; VEGF, vascular endothelial growth factor. concentration between the $\mathrm{NPA}^{+}$and $\mathrm{NPA}^{-}$groups did not reach significance, probably because of the small number of patients. Noma et al also reported that the aqueous VEGF level was significantly positively correlated both with the size of the NPA and the CRT in BRVO. ${ }^{12}$ We also found a significant positive correlation between the aqueous VEGF concentration and the size of the NPA. However, no correlation was found between the aqueous VEGF concentration and the CRT, although we had a greater number of patients. There is no previous report about this issue.

The reason could be the varying locations of the NPA in BRVO. Retinal vein occlusion develops at various sites and in areas of different sizes. Even when the NPA is relatively large, the foveal function could be affected less if the involved location is not near the macula. A second reason could be the localized effect of VEGF in BRVO. Sawada et al, who reported that the aqueous VEGF concentration in 21 eyes with myopic choroidal neovascularization was lower than in controls, speculated that the VEGF might be localized and cause choroidal neovascularization. ${ }^{20}$ Similarly, VEGF secreted from NPA distant from the macula might have little effect on the macula. Another reason could be the existence of SRF caused by other vascular permeability factors. We found that the CRT was significantly greater in BRVO eyes with SRF than without SRF, but the aqueous VEGF concentration and NPA was not different between them. This suggests that cytokines other than VEGF may be involved in BRVO. Indeed, it has been reported that inflammatory cytokines, such as IL-6, IL-8, and monocyte chemoattractant protein 1 may contribute to the pathogenesis of macular edema with BRVO, even in nonischemic BRVO. ${ }^{21}$ Therefore, inflammation could also elevate the VEGF level along with inflammatory cytokines.

\section{Conclusion}

The aqueous VEGF concentration in treatment-naive eyes with macular edema secondary to BRVO increased significantly and was correlated with the size of the NPA. The aqueous VEGF concentration significantly increased even in BRVO eyes without apparent NPA, suggesting that micro-disperfusion and/or inflammatory change may increase VEGF. The location and size of the NPA and the effect of locally secreted VEGF also seem to be important, because the VEGF was not correlated with the CRT.

\section{Acknowledgments}

This study was supported in part by a grant from the Ministry of Education, Culture, Sports, Science and Technology of 
Japan (24592668) and a grant from the Ministry of Health, Labour and Welfare. The authors have no proprietary interest in any aspect of this study.

\section{Disclosure}

The authors report no conflicts of interest in this work.

\section{References}

1. Michels RG, Gass JD. The natural course of retinal branch vein obstruction. Trans Am Acad Ophthalmol Otolaryngol. 1974;78:OP166-OP177.

2. Gutman FA, Zegarra H. The natural course of temporal retinal branch vein occlusion. Trans Am Acad Ophthalmol Otolaryngol. 1974;78: OP178-OP192.

3. Aiello LP, Avery RL, Arrigg PG, et al. Vascular endothelial growth factor in ocular fluid of patients of diabetic retinopathy and other retinal disorders. N Engl J Med. 1994;331:1480-1487.

4. Chen KH, Wu CC, Roy S, Lee SM, Liu JH. Increased interleukin-6 in aqueous humor of neovascular glaucoma. Invest Ophthalmol Vis Sci. 1999;40:2627-2632.

5. Pe'er J, Folberg R, Itin A, Gnessin H, Hemo I, Keshet E. Vascular endothelial growth factor upregulation in human central retinal vein occlusion. Ophthalmology. 1998;105:412-416.

6. Dvorak HF, Brown LF, Detmar M, Dvorak AM. Vascular permeability factor/vascular endothelial growth factor, microvascular hyperpermeability, and angiogenesis. Am J Pathol. 1995;146:1029-1039.

7. Vinores SA, Derevjanik NL, Ozaki H, Okamoto N, Campochiaro PA. Cellular mechanisms of blood-retinal barrier dysfunction in macular edema. Doc Ophthalmol. 1999;97:217-228.

8. Gardner TW, Antonetti DA, Barber AJ, Lieth E, Tarbell JA. The molecular structure and function of the inner blood-retinal barrier. Penn State Retina Research Group. Doc Ophthalmol. 1999;97:229-237.

9. Mulcahy MF, Benson AB III. Bevacizumab in the treatment of colorectal cancer. Expert Opin Biol Ther. 2005;5:997-1005.

10. Iturralde D, Spaide RF, Meyerle CB, et al. Intravitreal bevacizumab (Avastin) treatment of macular edema in central retinal vein occlusion: a short-term study. Retina. 2006;26:279-284.
11. Pai SA, Shetty R, Vijayan PB, et al. Clinical, anatomic, and electrophysiologic evaluation following intravitreal bevacizumab for macular edema in retinal vein occlusion. Am J Ophthalmol. 2007;143:601-606.

12. Noma H, Funatsu H, Yamasaki M, et al. Pathogenesis of macular edema with branch retinal vein occlusion and intraocular levels of vascular endothelial growth factor and interleukin-6. Am J Ophthalmol. 2005; 140:256-261.

13. Noma H, Minamoto A, Funatsu H, et al. Intravitreal levels of vascular endothelial growth factor and interleukin-6 are correlated with macular edema in branch retinal vein occlusion. Graefes Arch Clin Exp Ophthalmol. 2006;244:309-315.

14. Noma H, Funatsu H, Yamasaki M, et al. Aqueous humour levels of cytokines are correlated to vitreous levels and severity of macular oedema in branch retinal vein occlusion. Eye (Lond). 2008;22:42-48.

15. Stefansson E. The therapeutic effects of retinal laser treatment and vitrectomy: a theory based on oxygen and vascular physiology. Acta Ophthalmol Scand. 2001;79:435-440.

16. Arnarsson A, Stefansson E. Laser treatment and the mechanism of edema reduction in branch retinal vein occlusion. Invest Ophthalmol Vis Sci. 2000;41:877-879.

17. Silva RM, Faria de Abreu JR, Cunha-Vaz JG. Blood-retina barrier in acute retinal branch vein occlusion. Graefes Arch Clin Exp Ophthalmol. 1995;233:721-726.

18. Saika S, Tanaka T, Miyamoto T, Ohnishi Y. Surgical posterior vitreous detachment combined with gas/air tamponade for treating macular edema associated with branch retinal vein occlusion: retinal tomography and visual outcome. Graefes Arch Clin Exp Ophthalmol. 2001;239: 729-732.

19. Yamaguchi Y, Otani T, Kishi S. Serous macular detachment in branch retinal vein occlusion. Retina. 2006;26:1029-1033.

20. Sawada O, Kawamura H, Kakinoki M, Sawada T, Ohji M. Vascular endothelial growth factor in the aqueous humour in eyes with myopic choroidal neovascularization. Acta Ophthalmol. 2011;89:459-462.

21. Yoshimura T, Sonoda K, Sugahara M, et al. Comprehensive analysis of inflammatory immune mediators in vitreoretinal diseases. PLoS One. 2009;4:e8158.
Clinical Ophthalmology

\section{Publish your work in this journal}

Clinical Ophthalmology is an international, peer-reviewed journal covering all subspecialties within ophthalmology. Key topics include: Optometry; Visual science; Pharmacology and drug therapy in eye diseases; Basic Sciences; Primary and Secondary eye care; Patient Safety and Quality of Care Improvements. This journal is indexed on

\section{Dovepress}

PubMed Central and CAS, and is the official journal of The Society of Clinical Ophthalmology (SCO). The manuscript management system is completely online and includes a very quick and fair peer-review system, which is all easy to use. Visit http://www.dovepress.com/ testimonials.php to read real quotes from published authors. 